\title{
Dietary intervention modifies DNA methylation age assessed by the epigenetic clock
}

Article

Accepted Version

Sae-Lee, C., Corsi, S., Barrow, T. M., Kuhnle, G. G. C., Bollati, V., Mathers, J. C. and Byun, H.-M. (2018) Dietary intervention modifies DNA methylation age assessed by the epigenetic clock. Molecular Nutrition \& Food Research, 62 (23). 1800092. ISSN 1613-4125 doi: https://doi.org/10.1002/mnfr.201800092 Available at https://centaur.reading.ac.uk/80125/

It is advisable to refer to the publisher's version if you intend to cite from the work. See Guidance on citing.

To link to this article DOI: http://dx.doi.org/10.1002/mnfr.201800092

Publisher: Wiley

All outputs in CentAUR are protected by Intellectual Property Rights law, including copyright law. Copyright and IPR is retained by the creators or other copyright holders. Terms and conditions for use of this material are defined in the End User Agreement.

www.reading.ac.uk/centaur 
Central Archive at the University of Reading

Reading's research outputs online 


\section{Dietary intervention modifies DNA methylation age assessed by the epigenetic clock}

Chanachai Sae-Lee ${ }^{1,2}$, Sarah Corsi ${ }^{1}$, Timothy M Barrow ${ }^{3}$, Gunter G C Kuhnle ${ }^{4}$, Valentina Bollati $^{5}$, John C Mathers ${ }^{1}$, Hyang-Min Byun ${ }^{1 *}$

${ }^{1}$ Human Nutrition Research Centre, Institute of Cellular Medicine, Newcastle University, Newcastle Upon Tyne, UK

${ }^{2}$ Research division, Faculty of Medicine, Siriraj Hospital, Mahidol University, Bangkok, Thailand

${ }^{3}$ Faculty of Health Sciences and Wellbeing, University of Sunderland, Sunderland, UK ${ }^{4}$ Department of Food \& Nutritional Sciences, University of Reading, Whiteknights, UK

${ }^{5}$ EPIGET - Epidemiology, Epigenetics and Toxicology Lab, Department of Clinical Sciences and Community Health, University of Milan, Milano, Italy

* Corresponding author:

Dr. Hyang-Min Byun

Human Nutrition Research Centre

Institute of Cellular Medicine

Newcastle University, Newcastle Upon Tyne, UK, +447762212972

hyang-min.byun@ncl.ac.uk

Received: 24/01/2018; Revised: 19/08/2018; Accepted: 25/08/2018

This article has been accepted for publication and undergone full peer review but has not been through the copyediting, typesetting, pagination and proofreading process, which may lead to differences between this version and the Version of Record. Please cite this article as doi: $\underline{10.1002 / \mathrm{mnfr} .201800092 .}$. 
Short running head: Dietary intervention and epigenetic clock

\author{
Abbreviations \\ DNMT: DNA methyltransferases \\ MOF: monomeric and oligomeric flavanols \\ MTHFR: methylenetetrahydrofolate reductase \\ SAM: S-adenosyl-L-methionine \\ DAC: decitabine
}

Keywords: DNA methylation, MTHFR, folic acid, vitamin $\mathrm{B}_{12}$, MOF, Infinium 450K, DNAm age

\begin{abstract}
Scope: Alterations in DNA methylation patterns are correlated with aging, environmental exposures and disease pathophysiology; the possibility of reverting or preventing these processes through dietary intervention is gaining momentum. In particular, methyl donors that provide $S$-adenosyl-methionine for one-carbon metabolism and polyphenols such as flavanols that inhibit the activity of DNA methyltransferases (DNMTs) could be key modifiers of epigenetic patterns.
\end{abstract}

Methods and results: We assessed DNA methylation patterns in publicly available Illumina Infinium $450 \mathrm{~K}$ methylation datasets from intervention studies with either folic acid + vitamin $\mathrm{B}_{12}$ (GSE74548) or monomeric and oligomeric flavanols (MOF) (GSE54690) in 44 and 13 participants, respectively. Global DNA methylation levels increased in unmethylated regions such as $\mathrm{CpG}$ islands and shores following folic acid + vitamin $\mathrm{B}_{12}$ supplementation and de- 
creased in highly methylated regions, including shelves and open-seas following intervention with MOF. After supplementation with folic acid + vitamin $B_{12}$, epigenetic age, estimated by the Horvath 'epigenetic clock' model, was reduced in women with the MTHFR 677CC genotype.

Conclusions: The effects of supplementation with folic acid + vitamin $\mathrm{B}_{12}$ and MOF on DNA methylation age are dependent upon gender and MTHFR genotype. Additionally, our findings demonstrate the potential for these dietary factors to modulate global DNA methylation profiles.

\section{Graphical abstracts:}

We examined the effects of dietary supplementation with folic acid+vitamin $\mathrm{B}_{12}$ and flavanols upon global epigenetic patterns and epigenetic age. We observed increased methylation at $\mathrm{CpG}$ islands and shores following folic acid+vitamin $\mathrm{B}_{12}$, and decreased methylation at shelf and open sea regions after flavanols supplementation. Epigenetic age was decelerated by folic acid+vitamin $\mathrm{B}_{12}$, but only in women with MTHFR 677CC. 


\section{Graphical Abstracts}

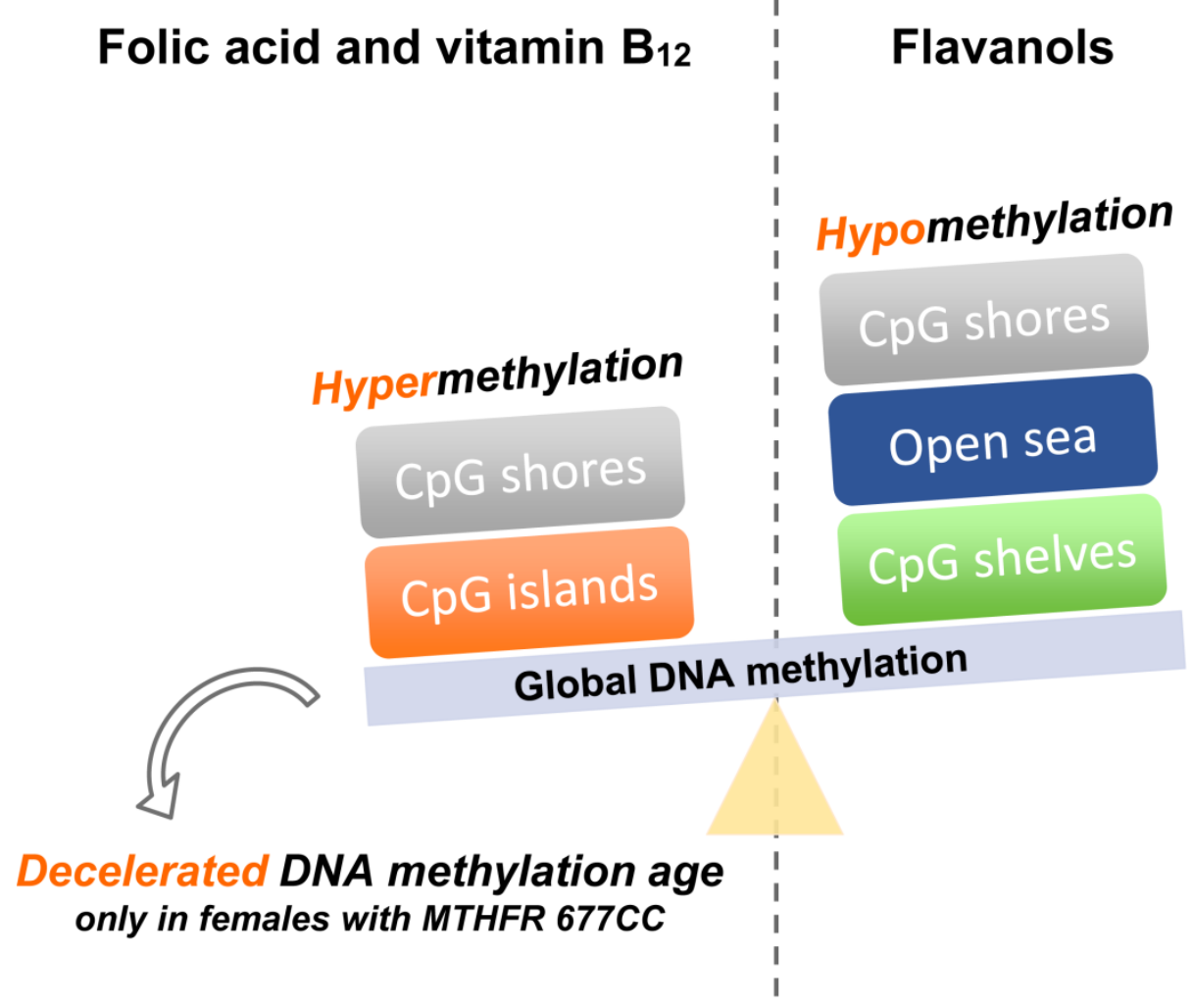

\section{Introduction}

DNA methylation is an epigenetic mark that enables the regulation of gene expression and, thereby, diverse biological processes including embryonic development, genomic imprinting, and aging. Aberrant DNA methylation patterns are implicated in multiple common diseases such as lung cancer, cardiovascular diseases, and metabolic disorders [1-6]. This epigenetic mark involves the covalent addition of a methyl group from $S$-adenosyl-L-methionine (SAM), the universal methyl donor, to the C-5 position of cytosine bases by DNA methyltransferases (DNMTs) [7]. SAM is generated via one-carbon metabolism comprising the folate and methionine cycles which includes the conversion of 5,10-methylenetetrahydrofolate to 5-methyltetrahydrofolate that is catalyzed by methylenetetrahydrofolate reductase (MTHFR). The most well-characterized polymorphism in MTHFR, substitution of cytosine 
by thymine at position 677 (C677T) in exon 4, leads to genotype and dose-dependent reduced activity of the enzyme, which causes increased homocysteine and decreased folate concentrations and these are associated with higher risk for age-associated diseases such as diabetes, vascular disease, and Down syndrome [8-10]. Although MTFHR genotype has been associated with changes in DNA methylation pattern in some studies [11], few effects were observed in a recent meta-analysis of pooled data from almost 10,000 individuals [12].

Nutrients and other food components can modify DNA methylation patterns [13] to modulate biological functions that influence health and aging. Higher intakes or status of several micronutrients participate in one-carbon metabolism, including folate, choline, betaine, methionine, vitamin $\mathrm{B}_{6}$, and vitamin $\mathrm{B}_{12}$, which contribute to $\mathrm{SAM}$ production are associated with increased DNA methylation $[14,15]$. Other nutrients, including flavanols and (-)epigallocatechin-3-gallate (EGCG), are competitive inhibitors of DNMTs through binding within the active site of the enzyme [16], and leading to decreased global DNA methylation. Many studies support the hypothesis that dietary compounds can modify DNA methylation patterns and influence the aging process [17]. An increasing body of evidence also suggests that the discrepancy between chronological age and DNA methylation age (DNAm age), that is an estimate of biological age determined by assessment of DNA methylation at $353 \mathrm{CpG}$ sites across the genome [18], is associated with risk of age-related diseases such as diabetes, obesity, cancer, and cardiovascular disease [19, 20].

In this study, we investigated the effect of supplementation with folic acid + vitamin $\mathrm{B}_{12}$ as a methyl donor and flavanols as DNMT inhibitors upon global DNA methylation profiles, including estimates of DNA m age, using publicly available Illumina Infinium 450K methylation datasets. We observed that DNAm age estimated by Horvath's model was altered by gender and MTHFR 677CC genotype following dietary intervention. 


\section{Materials and Methods}

\section{Study design}

We utilized publicly available Illumina Infinium 450K datasets from two separate dietary intervention studies. Ethical approval for the studies was granted by the institutional Medical Ethics Committee [21] and the Medical Ethical Committee of Maastricht University and Academic Hospital Maastricht [22]. In the first intervention study, 44 older participants (65-75 years) were randomized to supplementation with folic acid (400 $\mu \mathrm{g} / \mathrm{day})$ and vitamin $\mathrm{B}_{12}$ $(500 \mu \mathrm{g} /$ day) for two years. DNA methylation profiles before and after the intervention was measured in blood by Illumina Infinium $450 \mathrm{~K}$ microarray and the dataset was made available through the Gene Expression Omnibus (GSE74548)[21]. MTHFR genotype was also available from the study. The second intervention study was a non-randomized trial in which 13 non-obese, healthy male smokers (aged 30-60 years) were supplemented with monomeric and oligomeric flavanols (MOF; $200 \mu \mathrm{g} /$ day) for 8 weeks. No genotype data was available from this study. DNA methylation profiles before and after the intervention were measured in blood by Illumina Infinium $450 \mathrm{~K}$ microarray and the dataset was made available through the Gene Expression Omnibus (GSE54690)[22]. The characteristic of participants in both intervention studies are summarized in Table 1. For comparison with the effects of MOF, we also utilized a dataset of DNA methylation profiles from a study in which primary acute myeloid leukemia (AML) cells were treated with low-dose decitabine (DAC) (GSE40870) [23].

\section{Data analysis}

Datasets normalized by the SWAN procedure were used for our analysis [24]. Since we examined each intervention study separately, we did not normalize the two data sets together. Probes with detection $p$-value $>0.05$ were excluded [21-23], sex chromosomes and SNP10 
probes [25] were also excluded. The annotations for TSS200, TSS1500, 5'UTR, 3' UTR, $1^{\text {st }}$ exon, and gene body were acquired from the Illumina annotation file. For all datasets, global DNA methylation was determined by calculating the average across all interrogated $\mathrm{CpG}$ sites, and also in genomic regions ( $\mathrm{CpG}$ islands, shores, shelves, and open-sea areas) with characteristically different CpG density. DNA methylation age was calculated by the Horvath 'epigenetic clock' model using the online tool (https://dnamage.genetics.ucla.edu/), and methylation data for $353 \mathrm{CpG}$ loci as described previously [26].

\section{Statistics}

The effects of folic acid + vitamin $\mathrm{B}_{12}$ and of MOF on global DNA methylation were analyzed using paired-sample $t$-tests and ANOVA test. Both datasets were assessed for normality and revealed to be normally distributed, and therefore suitable for parametric testing (Supplemental Table 1). Paired sample $t$-tests were used to identify significant changes in global DNA methylation following MOF treatment, and age acceleration residuals among women with the MTHFR 677CC genotype. Repeated measures ANOVA was used to identify significant changes in global DNA methylation, DNA methylation age and age acceleration residuals of dietary interventions in relation to MTHFR genotype, gender and CpG density. Pearson's correlation coefficient was use to compare DNA methylation before and after the interventions. All analyses were performed using the IBM SPSS statistical software (version 24); data are presented as means $\pm \mathrm{SD}$, and $p$-values $<0.05$ were considered to be significant.

\section{Results}

Global DNA methylation changes by CpG density following supplementation with folic acid + vitamin $B_{12}$ or with $M O F$ 
Global DNA methylation was calculated as the mean beta value across all loci on the Illumina Infinium microarray after excluding 47,788 loci from the sex chromosomes and SNPassociated loci. Global DNA methylation was not significantly changed after MOF supplementation $(\Delta \beta=-0.013 \pm 0.02, p=0.71$, paired sample $t$-test) (Figure 1A). In contrast, folic acid + vitamin $\mathrm{B}_{12}$ supplementation increased global DNA methylation $(\Delta \beta=0.003 \pm 0.01 ; p=0.01$, repeated measures ANOVA) (Figure 1B). Furthermore, the effect of supplementation with folic acid + vitamin $\mathrm{B}_{12}$ intervention displayed an interaction with MTHFR genotype ( $p=0.01$ ), with increased methylation among those with the MTHFR 677CC genotype $(\Delta \beta=0.005 \pm 0.01)$ but not the 677TT genotype $(\Delta \beta<0.001 \pm 0.05)$ (Figure 1B).

Changes in DNA methylation following intervention were then analyzed at loci mapping to $\mathrm{CpG}$ islands, shores, shelves, and open-sea areas that have characteristically different CpG density. The mean baseline DNA methylation levels $\left({ }^{\circledR}\right)$ were 0.24 and 0.24 at $\mathrm{CpG}$ islands, 0.49 and 0.50 at north shores, 0.48 and 0.49 at south shores, 0.74 and 0.76 at north shelves, 0.74 and 0.77 at south shelves, and 0.70 and 0.72 in open sea areas for samples from the MOF and folic acid + vitamin $\mathrm{B}_{12}$ intervention studies, respectively (Figure 2A). Following dietary intervention, DNA methylation was altered in a supplement-specific manner $(p=0.01$, repeated measures ANOVA). DNA methylation at north shelves decreased after MOF intervention $(\Delta \beta=-0.003 \pm 0.00006)$, but increased after folic acid + vitamin $\mathrm{B}_{12}$ supplementation $(\Delta \beta=0.001 \pm 0.00006)$ (Figure $2 \mathrm{~B})$. DNA methylation at $\mathrm{CpG}$ islands increased after folic acid + vitamin $B_{12}$ supplementation $(\Delta \beta=0.003 \pm 0.00001)$, but decreased following MOF intervention $(\Delta \beta=-0.014 \pm 0.00007)$. However, these observed differences in DNA methylation change by genomic region were not statistically significant $(p=1.00)$.

Interestingly, we observed a similar pattern of greater decreases in DNA methylation at regions with lower $\mathrm{CpG}$ density in cells from $\mathrm{AML}$ patients following treatment with 
DAC, a DNA methyltransferase (DNMT) inhibitor (Figure 2C). The magnitude of change in DNA methylation was significantly greater with DAC treatment than with MOF supplementation $(p<0.001$, repeated measures ANOVA) and displayed an interaction with genomic region $(p=0.01)$, but the patterns of change by genomic region were very highly correlated $\left(\mathrm{R}^{2}=0.99, p\right.$-value $\left.<0.0001\right)$ (Figure 2D).

Change in DNA methylation age after supplementation with folic acid + vitamin $B_{12}$ or with $M O F$

The effect of dietary intervention upon DNA methylation age was assessed using Horvath's 'epigenetic clock' model [26], for both intervention studies (Figure 3A and B). We calculated age acceleration residuals, defined as the regression of DNAm age on chronological age. Age acceleration did not significantly change following the interventions: the difference between means were $-0.337 \pm 2.061$ for MOF $(p=0.87)$ and $-0.765 \pm 1.435$ for folic acid + vitamin $\mathrm{B}_{12}$ ( $p=0.60$ ) (Figure $3 \mathrm{C}$ and D). However, differential methylation at the 353 epigenetic clock loci was observed in an intervention-specific manner similar to that across the wider genome. Increased methylation was observed at the loci following folic acid + vitamin $\mathrm{B}_{12}$ supplementation, while reduced methylation was observed following MOF supplementation $(p=0.01$, repeated measures ANOVA). Similar effects were observed across all genomic regions, with no interaction between the form of dietary supplementation and $\mathrm{CpG}$ density $(p=0.76)$ (Figure $3 \mathrm{E})$.

DNA methylation age after folic acid + vitamin $B_{12}$ supplementations by gender and MTHFR genotype 
We analyzed the age acceleration residual by gender and MTHFR genotype for participants in the folic acid + vitamin $\mathrm{B}_{12}$ intervention study. Age acceleration residuals in females with the MTHFR 677CC genotype displayed the greatest change following dietary intervention $(\Delta \mathrm{re}-$ sidual $=-2.70)$ in comparison to males with the same genotype $(\Delta$ residual $=-0.75)$, and females and males with the 677TT genotype ( $\Delta$ residual $=0.16$ and 0.76 respectively) (Figure 4$)$. While the influence of genotype ( $p=0.16$, repeated measures ANOVA), gender $(p=0.41)$ and their interaction $(p=0.67)$ upon response to intervention were not statistically significant across all participants, we observed a significant reduction in age acceleration solely among women with the MTHFR $677 \mathrm{CC}$ genotype ( $p=0.04$, paired sample $t$-test). Furthermore, interestingly, we observed that age acceleration in males with the MTHFR 677TT genotype was higher than those with the MTHFR $677 \mathrm{CC}$ at baseline $(\Delta \mathrm{means}=6.014 \pm 2.422)$ and this relationship was unaltered following intervention $(\Delta$ means $=7.529 \pm 2.864)$ (Figure 4).

\section{Discussion}

Several dietary factors modify epigenetic patterns [13]. These include vitamins that contribute to the production of the methyl donor SAM via one-carbon metabolism e.g. polyphenols that inhibit of DNMT activity. Using publically-available datasets, our study has demonstrated that supplementation with folic acid + vitamin $\mathrm{B}_{12}$ alters global DNA methylation, with differential effects of intervention agents by genomic domain, MTHFR genotype and gender.

We observed that supplementation with folic acid + vitamin $\mathrm{B}_{12}$ increased global DNA methylation levels in individuals with the MTHFR 677CC but not the MTHFR 677TT genotype, and that this effect was greatest in $\mathrm{CpG}$ islands and shores that are characteristically CpG-dense regions. The T version of the MTHFR C677T polymorphism results in the substitution of an alanine residue with a valine, leading to a $50 \%$ reduction in enzymatic activity, 
and $10-20 \%$ of individuals in Western Europe and North America have the 677TT genotype $[27,28]$. Observational studies have reported that higher levels of folic acid and vitamin $B_{12}$ in the diet are associated with higher global DNA methylation levels [14, 15]. However, contrary to our findings, Jung et al [29] reported no significant effect of supplementation with $0.8 \mathrm{mg}$ folic acid/d on global DNA methylation even when MTHFR genotype was taken into account. We speculate that this discrepancy may be due to differences in methodology used for quantifying global DNA methylation. Jung et al used a liquid chromatography-tandem mass spectrometry approach that quantifies all methylated cytosines relative to total cytosine in the genome. In contrast, we used data from the Illumina Infinium DNA methylation microarray platform that interrogates more than 450,000 specific cytosine residues that are located predominantly in $\mathrm{CpG}$-dense regions such as $\mathrm{CpG}$ islands that we observed were more susceptible to the effects of folic acid + vitamin $\mathrm{B}_{12}$.

The 'epigenetic clock' model developed by Horvath [18] provides estimates of DNAm age - a putative measure of biological age. This model integrates DNA methylation at $353 \mathrm{CpG}$ sites that map to genes associated with cell survival and development and that may measure the cumulative effect of an epigenetic maintenance system [18]. Age acceleration, where the calculated DNAm age exceeds chronological age, has been observed in the liver of obese individuals [30], is associated with the development of age-associated diseases such as Parkinson's disease [34] and coronary heart disease [31], and has demonstrated links with all-cause mortality in multiple studies [32-34]. Recent investigation of observational studies has shown that higher intakes of fish and vegetables are associated with reduced epigenetic aging using an enhanced version of an alternative model developed by Hannum et al [35]. Our study identified an association between dietary supplementation with folic acid + vitamin $\mathrm{B}_{12}$ and decreased epigenetic aging, but only in women with the MTHFR $677 \mathrm{CC}$ 
genotype. Women might need less folate supplementation due to differences in body mass by gender [36], and therefore higher doses of folate may be required to produce the same biological effect in men. This is supported by the finding that, following folic acid $+\operatorname{vitamin} \mathrm{B}_{12}$ intervention study, serum folate concentration was higher among women than men, and highest of all among women with the 677CC genotype (data not shown). We observed no significant correlation directly between age acceleration residuals and serum folate, serum vitamin $\mathrm{B}_{12}$ or plasma homocysteine levels (data not shown), thereby underlining the complex interaction between dietary intake, genotype and epigenetic aging. Interestingly, our study also revealed significantly higher DNAm among men with the MTHFR 677TT genotype in comparison to those with the $\mathrm{CC}$ genotype irrespective of dietary intervention, but this was not the case among women. To the best of our knowledge, our observation of reduced epigenetic aging following folic acid + vitamin $B_{12}$ supplementation is the first reported effect of MTHFR genotype on DNA methylation in women, and may suggest that women with the more common $677 \mathrm{CC}$ genotype may benefit particularly from such supplementation. Notably, previous studies into genotype by gender interactions in response to folate have been conducted in populations with low folate intake, and we speculate that such gender and genotype effects may become apparent only when folate intake/ status is higher. Further work is required to elucidate how MTHFR activity may influence the epigenetic aging process.

Indeed, there has recently been tremendous interest in the previously described epigenetic models of ageing, such as the 'epigenetic clock' model by Horvath [18], that of Hannum et al [37], and the age-associated epigenetic drift described by Teschendorff and colleagues [38]. Importantly, there is already substantial evidence to suggest that epigenetic ageing accelerates in response to lifestyles and exposures, such as tobacco smoke [33], stress [39] and obesity [30], and also with outcomes such as all-cause mortality [40]. However, the 
changes in DNA methylation at the loci incorporated into these models are predominantly small in effect size. Furthermore, a recent study by Maegawa et al. [41] reported that the rate of epigenetic drift is correlated with lifespan. Mice, with a maximum longevity of 4 years, show $1 \%$ drift in DNA methylation per year, while rhesus monkeys (maximum longevity: 40 years) show drift of $0.3 \%$ per year and humans (maximum longevity: 122.5 years) $0.1 \%$ per year. Maegawa et al. demonstrate that caloric restriction is able to reduce this DNA methylation drift, which may therefore help to explain the association of increased longevity after caloric restriction. As Breton et al. have discussed [42], many epigenetic epidemiology studies have reported $1-5 \%$ changes in DNA methylation in response to environmental exposures, whether measuring gene-specific or global DNA methylation (frequently using LINE-1 and Alu as surrogate markers). In the context of epigenetic drift with aging, it can be interpreted that a $1 \%$ change in DNA methylation in response to environmental exposures is equivalent to 10 years' worth of natural epigenetic drift. Most environmental epigenetic studies utilize blood as the tissue in which to measure DNA methylation, and Issa has hypothesized that it could be possible to use epigenetic drift in blood as a surrogate for other tissues [43]. This, of course, would need to be examined carefully, and further work is required to establish how changes observed in blood may correlate with life expectancy. Nonetheless, there is sufficient evidence to support the hypothesis that small magnitude changes in DNA methylation, particularly when occurring at the pre- or post-natal stage, could be biologically significant in the context of representing epigenetic drift and the health consequences later in life.

Our study has limitations. Firstly, the designs of the two independent intervention studies that we used differed in several respects including gender and age distribution of participants, and the duration of intervention. Because of this limitation, we chose to examine data from each independently, in parallel. Secondly, the number of participants receiving 
folic acid + vitamin $B_{12}$ supplementation was relatively small $(n=44)$ and so our observation of effects of gender and MTHFR genotype on DNA methylation patterns and on epigenetic age acceleration will need to be confirmed in future studies. In addition, it is likely that we did not have sufficient statistical power to detect other interactions. We therefore took steps to minimize potential sources of variability in order to maximize our potential to observe biological changes. The intervention studies used for our analysis were performed in healthy, non-obese individuals who were non-smokers and did not drink alcohol excessively (folic acid + vitamin B12 intervention) or who were male smokers (MOF). The pairwise analysis of samples from participants before and after intervention enabled us to control for a number of potential confounding factors, and we stratified our analysis by gender, MTHFR genotype and by use of age acceleration residuals, which are not correlated with chronological age.

In summary, for the first time, we report that supplementation with folic acid + vitamin $\mathrm{B}_{12}$ or with monomeric and oligomeric flavanols can modify DNA methylation patterns and that these effects differ by intervention agent and by genomic location or $\mathrm{CpG}$ density. Further, the effect of folic acid + vitamin $\mathrm{B}_{12}$ supplementation appear to be gender- and MTHFR genotype-specific. If confirmed in future independent studies, these novel findings will strengthen the evidence base for personalized nutrition strategies which integrate genotypic data which may enhance the efficacy of dietary interventions [44]. Further work is required to determine the utility of these dietary compounds in the maintenance of normal epigenetic patterns for disease prevention. 


\section{Author contributions}

HMB designed the research; CSL, SC, and TMB analyzed the data; CSL, SC, GGCK, VB,

TMB, JCM, and HMB wrote the paper; HMB had primary responsibility for final content.

All authors read and approved the final manuscript.

\section{Acknowledgments}

None to report.

\section{Conflict of interest statement}

The authors have no conflict of interest to report.

\section{References}

[1] Barres, R., Zierath, J. R., DNA methylation in metabolic disorders. The American journal of clinical nutrition 2011, 93, 897S-900S.

[2] Baylin, S. B., DNA methylation and gene silencing in cancer. Nature clinical practice Oncology 2005, 2, S4-S11.

[3] Luczak, M. W., Jagodziński, P. P., The role of DNA methylation in cancer development. Folia histochemica et cytobiologica 2006, 44, 143-154.

[4] Magalhães, M., Rivals, I., Claustres, M., Varilh, J., Thomasset, M., Bergougnoux, A., Mely, L., Leroy, S., Corvol, H., Guillot, L., Murris, M., DNA methylation at modifier genes of lung disease severity is altered in cystic fibrosis. Clin Epigenetics 2017, 9, 19.

[5] Zhong, J., Agha, G., Baccarelli, A. A., The role of DNA methylation in cardiovascular risk and disease. Circulation research 2016, 118, 119-131.

This article is protected by copyright. All rights reserved. 
[6] Byun, H.M., Eshaghian, S., Douer, D., Trent, J., Garcia-Manero, G., Bhatia, R., Siegmund, K., Yang, A.S., Impact of Chromosomal Rearrangement upon DNA Methylation Patterns in Leukemia. Open Med (Wars) 2017, 12, 76-85.

[7] Robertson, K. D., DNA methylation and human disease. Nat Rev Genet 2005, 6, 597-610.

[8] Castro, R., Rivera, I., Ravasco, P., Jakobs, C., Blom, H.J., Camilo, M.E., De Almeida, I.T., 5,10-Methylenetetrahydrofolate reductase 677C-->T and 1298A-->C mutations are genetic determinants of elevated homocysteine. QJM 2003, 96, 297-303.

[9] Fodinger, M., Horl, W. H., Sunder-Plassmann, G., Molecular biology of 5,10methylenetetrahydrofolate reductase. J Nephrol 2000, 13, 20-33.

[10] Hobbs, C.A., Cleves, M.A., Lauer, R.M., Burns, T.L., James, S.J., Preferential transmission of the MTHFR $677 \mathrm{~T}$ allele to infants with Down syndrome: implications for a survival advantage. Am J Med Genet 2002, 113, 9-14.

[11] Friso, S., Choi, S.W., Girelli, D., Mason, J.B., Dolnikowski, G.G., Bagley, P.J., Olivieri, O., Jacques, P.F., Rosenberg, I.H., Corrocher, R., Selhub, J., A common mutation in the 5,10methylenetetrahydrofolate reductase gene affects genomic DNA methylation through an interaction with folate status. Proc Natl Acad Sci U S A 2002, 99, 5606-5611.

[12] Mandaviya, P.R., Joehanes, R., Aïssi, D., Kühnel, B., Marioni, R.E., Truong, V., Stolk, L., Beekman, M., Bonder, M.J., Franke, L., Gieger, C., Genetically defined elevated homocysteine levels do not result in widespread changes of DNA methylation in leukocytes. PLoS One 2017, 12, e0182472.

[13] Mathers, J. C., Strathdee, G., Relton, C. L., Induction of epigenetic alterations by dietary and other environmental factors. Adv Genet 2010, 71, 3-39. 
[14] Pirouzpanah, S., Taleban, F. A., Mehdipour, P., Atri, M., Association of folate and other one-carbon related nutrients with hypermethylation status and expression of RARB, BRCA1, and RASSF1A genes in breast cancer patients. J Mol Med (Berl) 2015, 93, 917-934.

[15] Piyathilake, C.J., Johanning, G.L., Macaluso, M., Whiteside, M., Oelschlager, D.K., Heimburger, D.C., Grizzle, W.E., Localized folate and vitamin B-12 deficiency in squamous cell lung cancer is associated with global DNA hypomethylation. Nutr Cancer 2000, 37, 99107.

[16] Fang, M.Z., Wang, Y., Ai, N., Hou, Z., Sun, Y., Lu, H., Welsh, W., Yang, C.S., Tea polyphenol (-)-epigallocatechin-3-gallate inhibits DNA methyltransferase and reactivates methylation-silenced genes in cancer cell lines. Cancer Res 2003, 63, 7563-7570.

[17] Mathers, J. C., Nutritional modulation of ageing: genomic and epigenetic approaches. Mech Ageing Dev 2006, 127, 584-589.

[18] Horvath, S., DNA methylation age of human tissues and cell types. Genome Biol 2013, 14, R115.

[19] Perna, L., Zhang, Y., Mons, U., Holleczek, B., Saum, K.U., Brenner, H., Epigenetic age acceleration predicts cancer, cardiovascular, and all-cause mortality in a German case cohort. Clinical epigenetics 2016, 8, 64.

[20] Horvath, S., Erhart, W., Brosch, M., Ammerpohl, O., von Schönfels, W., Ahrens, M., Heits, N., Bell, J.T., Tsai, P.C., Spector, T.D., Deloukas, P., Obesity accelerates epigenetic aging of human liver. Proceedings of the National Academy of Sciences 2014, 111, 1553815543.

[21] Kok, D.E., Dhonukshe-Rutten, R.A., Lute, C., Heil, S.G., Uitterlinden, A.G., van der Velde, N., van Meurs, J.B., van Schoor, N.M., Hooiveld, G.J., de Groot, L.C., Kampman, E., 
The effects of long-term daily folic acid and vitamin B 12 supplementation on genome-wide DNA methylation in elderly subjects. Clinical epigenetics 2015, 7, 121.

[22] Milenkovic, D., Berghe, W.V., Boby, C., Leroux, C., Declerck, K., vel Szic, K.S., Heyninck, K., Laukens, K., Bizet, M., Defrance, M., Dedeurwaerder, S., Dietary flavanols modulate the transcription of genes associated with cardiovascular pathology without changes in their DNA methylation state. PloS one 2014, 9, e95527.

[23] Milenkovic, D., Berghe, W.V., Boby, C., Leroux, C., Declerck, K., vel Szic, K.S., Heyninck, K., Laukens, K., Bizet, M., Defrance, M., Dedeurwaerder, S.,Genomic impact of transient low-dose decitabine treatment on primary AML cells. Blood 2013, 121, 1633-1643. [24] Aryee, M.J., Jaffe, A.E., Corrada-Bravo, H., Ladd-Acosta, C., Feinberg, A.P., Hansen, K.D., Irizarry, R.A., Minfi: a flexible and comprehensive Bioconductor package for the analysis of Infinium DNA methylation microarrays. Bioinformatics 2014, 30, 1363-1369.

[25] Byun, H.M., Siegmund, K.D., Pan, F., Weisenberger, D.J., Kanel, G., Laird, P.W., Yang, A.S., Epigenetic profiling of somatic tissues from human autopsy specimens identifies tissueand individual-specific DNA methylation patterns. Hum Mol Genet 2009, 18, 4808-4817.

[26] Horvath, S., DNA methylation age of human tissues and cell types. Genome biology $2013,14,3156$

[27] Liew, S. C., Gupta, E. D., Methylenetetrahydrofolate reductase (MTHFR) C677T polymorphism: epidemiology, metabolism and the associated diseases. Eur J Med Genet 2015, $58,1-10$.

[28] Russo, G.T., Friso, S., Jacques, P.F., Rogers, G., Cucinotta, D., Wilson, P.W., Ordovas, J.M., Rosenberg, I.H., Selhub, J., Age and gender affect the relation between methylenetetrahydrofolate reductase C677T genotype and fasting plasma homocysteine concentrations in the Framingham Offspring Study Cohort. J Nutr 2003, 133, 3416-3421. 
[29] Jung, A.Y., Smulders, Y., Verhoef, P., Kok, F.J., Blom, H., Kok, R.M., Kampman, E., Durga, J., No effect of folic acid supplementation on global DNA methylation in men and women with moderately elevated homocysteine. PLoS One 2011, 6, e24976.

[30] Horvath, S., Erhart, W., Brosch, M., Ammerpohl, O., von Schönfels, W., Ahrens, M., Heits, N., Bell, J.T., Tsai, P.C., Spector, T.D., Deloukas, P., Obesity accelerates epigenetic aging of human liver. Proc Natl Acad Sci U S A 2014, 111, 15538-15543.

[31] Horvath, S., Gurven, M., Levine, M.E., Trumble, B.C., Kaplan, H., Allayee, H., Ritz, B.R., Chen, B., Lu, A.T., Rickabaugh, T.M., Jamieson, B.D., An epigenetic clock analysis of race/ethnicity, sex, and coronary heart disease. Genome biology 2016, 17, 171.

[32] Marioni, R.E., Harris, S.E., Shah, S., McRae, A.F., von Zglinicki, T., Martin-Ruiz, C., Wray, N.R., Visscher, P.M., Deary, I.J., The epigenetic clock and telomere length are independently associated with chronological age and mortality. Int J Epidemiol 2016.

[33] Perna, L., Zhang, Y., Mons, U., Holleczek, B., Saum, K.U., Brenner, H., Epigenetic age acceleration predicts cancer, cardiovascular, and all-cause mortality in a German case cohort. Clin Epigenetics 2016, 8, 64.

[34] Chen, B.H., Marioni, R.E., Colicino, E., Peters, M.J., Ward-Caviness, C.K., Tsai, P.C., Roetker, N.S., Just, A.C., Demerath, E.W., Guan, W., Bressler, J., DNA methylation-based measures of biological age: meta-analysis predicting time to death. Aging (Albany NY) 2016, $8,1844-1865$.

[35] Quach, A., Levine, M.E., Tanaka, T., Lu, A.T., Chen, B.H., Ferrucci, L., Ritz, B., Bandinelli, S., Neuhouser, M.L., Beasley, J.M., Snetselaar, L., Epigenetic clock analysis of diet, exercise, education, and lifestyle factors. Aging (Albany NY) 2017, 9, 419-446.

This article is protected by copyright. All rights reserved. 
[36] Winkels, R.M., Brouwer, I.A., Verhoef, P., van Oort, F.V., Durga, J., Katan, M.B., Gender and body size affect the response of erythrocyte folate to folic acid treatment. $J$ Nutr 2008, 138, 1456-1461.

[37] Hannum, G., Guinney, J., Zhao, L., Zhang, L., Hughes, G., Sadda, S., Klotzle, B., Bibikova, M., Fan, J.B., Gao, Y., Deconde, R., Genome-wide methylation profiles reveal quantitative views of human aging rates. Mol Cell 2013, 49, 359-367.

[38] Teschendorff, A. E., West, J., Beck, S., Age-associated epigenetic drift: implications, and a case of epigenetic thrift? Hum Mol Genet 2013, 22, R7-R15.

[39] Zannas, A.S., Arloth, J., Carrillo-Roa, T., Iurato, S., Röh, S., Ressler, K.J., Nemeroff, C.B., Smith, A.K., Bradley, B., Heim, C., Menke, A., Lifetime stress accelerates epigenetic aging in an urban, African American cohort: relevance of glucocorticoid signaling. Genome Biol 2015, 16, 266.

[40] Marioni, R.E., Shah, S., McRae, A.F., Chen, B.H., Colicino, E., Harris, S.E., Gibson, J., Henders, A.K., Redmond, P., Cox, S.R., Pattie, A., DNA methylation age of blood predicts all-cause mortality in later life. Genome Biol 2015, 16, 25.

[41] Maegawa, S., Lu, Y., Tahara, T., Lee, J.T., Madzo, J., Liang, S., Jelinek, J., Colman, R.J., Issa, J.P.J., Caloric restriction delays age-related methylation drift. Nat Commun 2017, $8,539$.

[42] Breton, C.V., Marsit, C.J., Faustman, E., Nadeau, K., Goodrich, J.M., Dolinoy, D.C., Herbstman, J., Holland, N., LaSalle, J.M., Schmidt, R., Yousefi, P., Small-Magnitude Effect Sizes in Epigenetic End Points are Important in Children's Environmental Health Studies: The Children's Environmental Health and Disease Prevention Research Center's Epigenetics Working Group. Environ Health Perspect 2017, 125, 511-526.

[43] Issa, J. P., Aging and epigenetic drift: a vicious cycle. J Clin Invest 2014, 124, 24-29. 
[44] Celis-Morales, C., Marsaux, C.F., Livingstone, K.M., Navas-Carretero, S., San-

Cristobal, R., Fallaize, R., Macready, A.L., O’Donovan, C., Woolhead, C., Forster, H., Kolossa, S., Can genetic-based advice help you lose weight? Findings from the Food4Me European randomized controlled trial. Am J Clin Nutr 2017, 105, 1204-1213.

Figure and table legends

Figure 1. Global DNA methylation between before and after dietary intervention. Mean global methylation levels following $\mathrm{MOF}$ (A) or folic acid + vitamin $\mathrm{B}_{12}(\mathrm{~B})$ supplementation. Mean \pm SD.

\section{Figure 1}
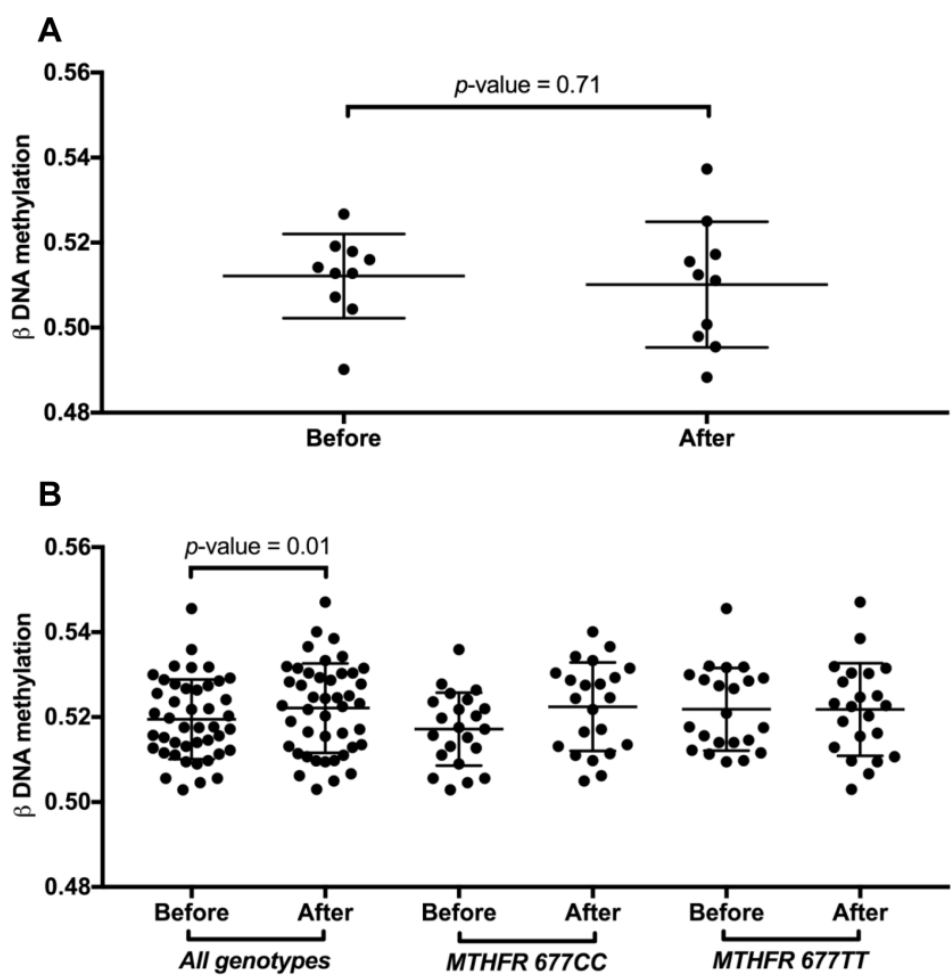

This article is protected by copyright. All rights reserved. 
Figure 2. Global DNA methylation by $\mathrm{CpG}$ density after intervention. Global DNA methylation by $\mathrm{CpG}$ density before the interventions (A), mean of global DNA methylation changes after the interventions (B), mean of global DNA methylation changes by $\mathrm{CpG}$ density after decitabine (DAC) treatment in acute myeloid leukemia patients $(\mathrm{C})$, and comparison of global DNA methylation changes by $\mathrm{CpG}$ density between DAC treatment and MOF intervention (D). Mean $\pm \mathrm{SD}$.

\section{Figure 2}
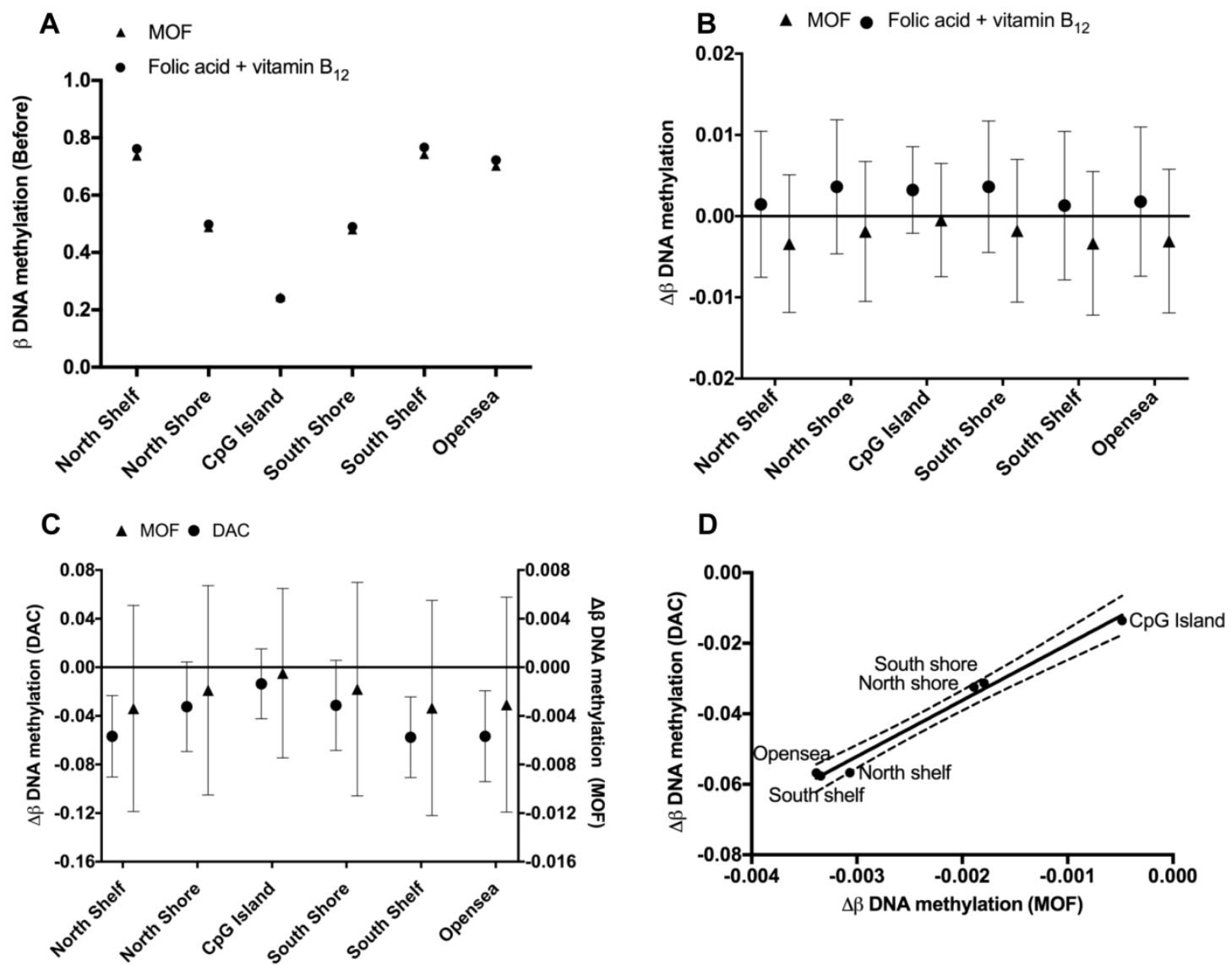

This article is protected by copyright. All rights reserved. 
Figure 3. DNAm age following dietary interventions. The correlation of DNAm age before and after MOF supplementation (A) and folic acid + vitamin $\mathrm{B}_{12}$ supplementation (B). Age acceleration residuals before and after MOF supplementation(C) and after folic acid + vitamin $\mathrm{B}_{12}$ supplementation (D). (E) DNA methylation changes at epigenetic clock loci by $\mathrm{CpG}$ density, with each data point corresponding to the average methylation change across the study participants for each of the 353 clock loci. Mean \pm SD. $* * *=p<0.001 ; * * * *=$ $\mathrm{p}<0.0001$

Figure 3
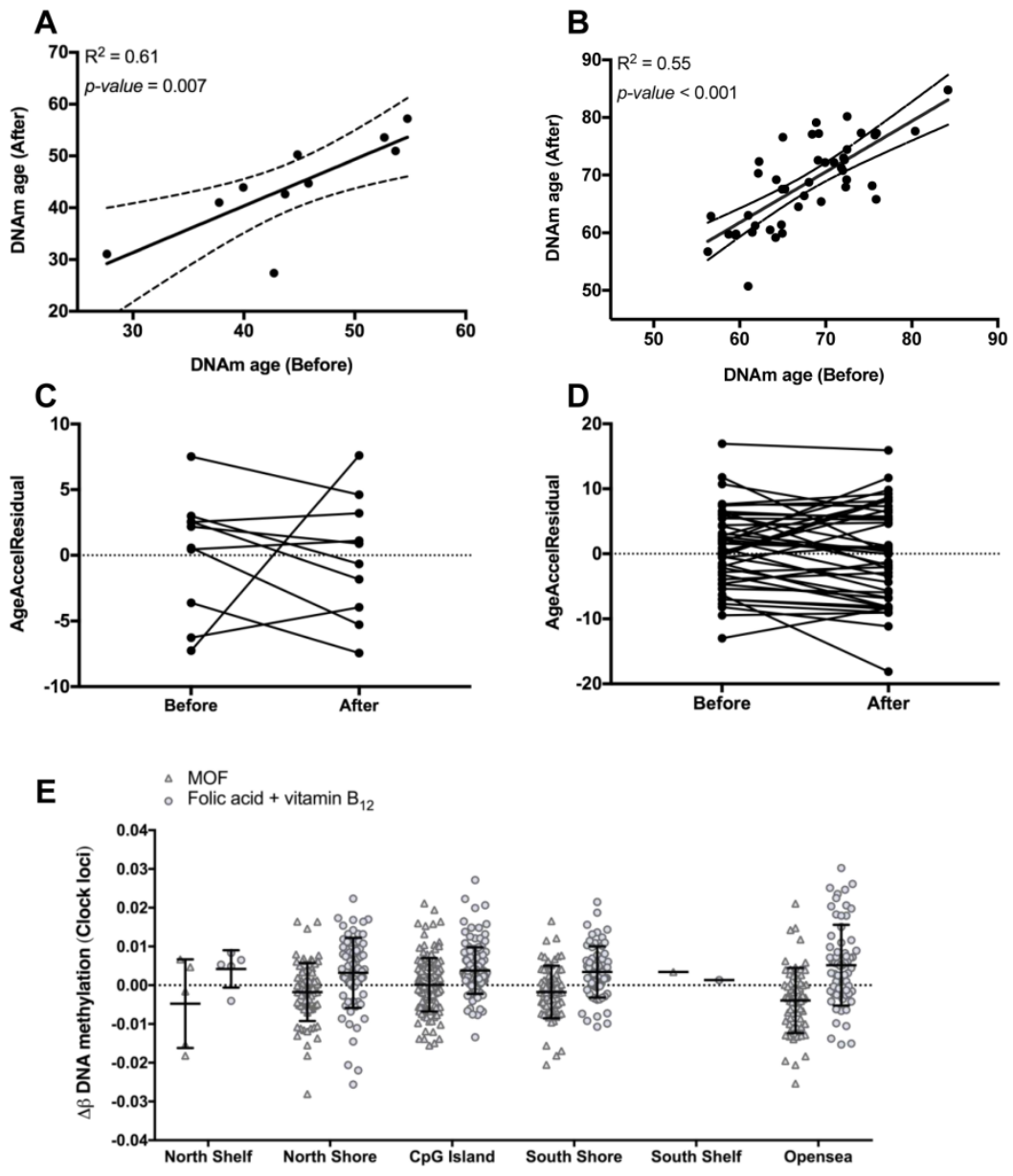
Figure 4. Age acceleration residuals before and after folic acid + vitamin $\mathrm{B}_{12}$ intervention by gender and MTHFR C677T genotypes. Mean \pm SD.

\section{Figure 4}

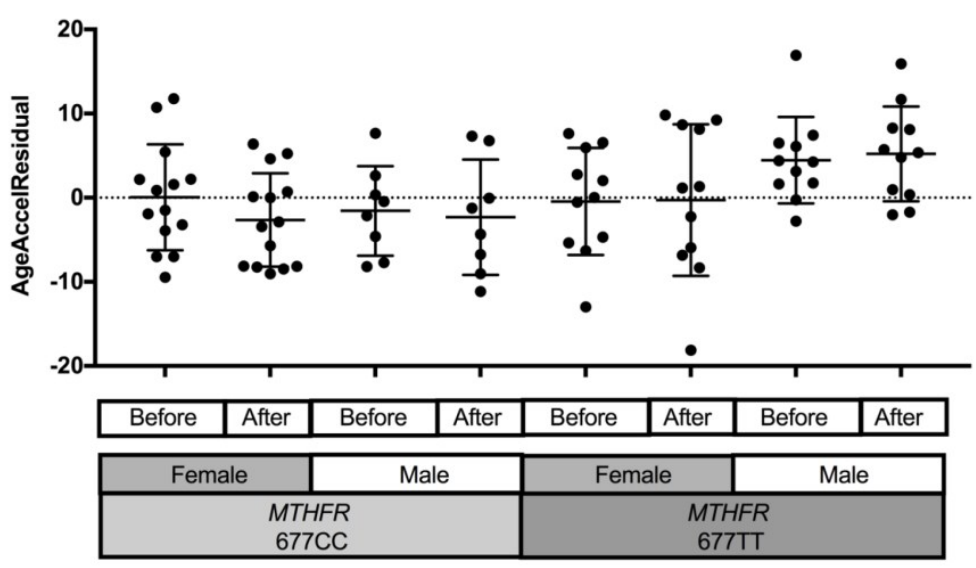

Supplemental Figure 1. The correlation between epigenetic age and serum folate (nmol/L), serum vitamin $\mathrm{B}_{12}(\mathrm{pmol} / \mathrm{L})$ and plasma homocysteine $(\mu \mathrm{mol} / \mathrm{L})$ by MTHFR genotype.

Table 1. The characteristics of participants in the MOF and folic acid + vitamin $\mathrm{B}_{12}$ intervention studies

Supplemental Table 1. Assessment of normality.

This article is protected by copyright. All rights reserved. 
